\title{
Metabolic cataracts in newly diagnosed diabetes
}

\author{
Vipan Datta, Peter G F Swift, Geoffrey H A Woodruff, Roy F Harris
}

\begin{abstract}
The morphologically distinct diabetic or 'metabolic' cataract is rare in newly diagnosed insulin dependent diabetes. The cases described are of five adolescents (three girls, two boys) with newly diagnosed insulin dependent diabetes who developed metabolic cataracts close to the time of diagnosis (0-16 months). They all had a prolonged duration of symptoms before diagnosis (4-24 months) and high glycated haemoglobin levels at diagnosis (15-21\%). The pathogenesis of diabetic cataract is not well understood in humans. An attempt is made to link clinical observations with evidence from experimental animal models to understand the mechanism of cataract formation, with particular reference to the aldose reductase pathway. It is recommended that the lens and retina are examined at the onset of diabetes in all children, especially those who have a prolonged duration of symptoms before diagnosis and who report persistent blurred vision.

(Arch Dis Child 1997;76:118-120)
\end{abstract}

Keywords: insulin dependent diabetes; metabolic cataracts; aldose reductase; sorbitol pathway.

Cataracts are more common in people with diabetes than in the general population under the age of 40 years $^{1}$ and they are morphologically similar to senile cataracts. Cataracts are uncommon in children and young adolescents with diabetes mellitus ${ }^{2}$ and are usually associated with prolonged poor metabolic control. ${ }^{13}$ These true diabetic, juvenile, or metabolic cataracts are characterised by diffuse posterior and/or anterior, subcapsular or cortical 'snowflake' opacities. Metabolic cataracts may develop acutely within weeks or months ${ }^{13}$ and there are reports of transient cataracts in children with diabetes which disappear with improved metabolic control. ${ }^{4-6}$ There are also a small number of case reports of cataracts either as the presenting feature of diabetes in children $^{13}{ }^{3-10}$ or developing soon after diagnosis in children ${ }^{1311}$ and young adults. ${ }^{12}$ These cataracts usually progress to maturity and cause blindness unless surgically removed.

This paper describes the cases of five adolescents with early diabetic cataracts in newly diagnosed insulin dependent diabetes. Details of the cases are given in table 1 .

Correspondence to: Dr Vipan Datta, Children's Hospital, Leicester Royal Infirmary, Leicester LE1 5Ww.

Accepted 29 October 1996
CASE 1

A 14 year old girl presented in 1994 with a 12 month history of polyuria and polydipsia. For six months she had noticed increasing lethargy and weight loss. There was no significant illness in the past and no family history of diabetes. On admission she was dehydrated and in diabetic ketoacidosis with a blood $\mathrm{pH}$ of 7.02. Her initial blood glucose concentration was $32.8 \mathrm{mmol} / \mathrm{l}$. She made an uncomplicated recovery using a standard diabetic ketoacidosis protocol with low dose insulin infusion. Glycated haemoglobin $\left(\mathrm{HbA}_{1}\right)$ at diagnosis was $15.1 \%$.

Three weeks later she reported blurred vision. An eye examination showed slight bilateral haziness of the lens with difficulty in focusing onto the retina. One month later she was still reporting fuzzy distant vision. The lenses were not obviously opaque, but difficulty was again experienced in focusing her retinal vessels. She was seen by the ophthalmologist three months after her diabetes was diagnosed. Her visual acuity was $6 / 9$ in both eyes. Ophthalmology confirmed early bilateral posterior subcapsular cataracts with a normal retina and fundus. Her vision deteriorated rapidly over the subsequent four months and she began to experience problems at school with reading and drawing up her insulin. Her visual acuity was $6 / 24$ (right) and 2/24 (left). An eye examination showed moderate bilateral posterior subcapsular cataracts. She had an operation on her left cataract with intraocular lens implantation. Her vision improved to $6 / 9$ unaided in the left eye. A cataract operation on her right eye was performed 14 months after diagnosis. Her quality of life has improved greatly and she is functioning well at school. Unaided vision is now $6 / 6$ in both eyes.

CASE 2

A 12 year old girl presented in 1979 with a one year history of polyuria, polydipsia, and weight loss. Her blood glucose concentration was 44 $\mathrm{mmol} / 1$ and $\mathrm{HbA}_{1} 21.2 \%$. Despite good diabetic control she reported difficulty in vision one year later, which worsened rapidly over the next four months to such an extent that she missed school for six weeks. She was found to have dense bilateral cataracts. She underwent bilateral cataract extraction followed by contact lens prescription.

CASE 3

A 13 year old girl presented in 1972 with a history of excessive thirst for two years. She also reported nocturia and lassitude for several months. Just before the diagnosis of diabetes she reported blurred vision and was prescribed glasses. Three months after diagnosis her visual acuity was $6 / 6$ in both eyes and ophthalmological examination confirmed bilateral cortical lens opacification. One year after diagnosis her 
Table 1 Characteristic features of the five reported cases

\begin{tabular}{lllllll}
\hline & $\begin{array}{l}\text { Age at } \\
\text { presentation } \\
\text { (years) }\end{array}$ & Sex & $\begin{array}{l}\text { Duration of } \\
\text { symptoms before } \\
\text { diagnosis (months) }\end{array}$ & $\begin{array}{l}\text { Initial blood } \\
\text { glucose } \\
\text { (mmoll) }\end{array}$ & $\begin{array}{l}\text { Initial } \\
\text { HbA } \\
(\%)\end{array}$ & $\begin{array}{l}\text { Time to appearance of } \\
\text { cataracts after diagnosis } \\
\text { of IDDM (months) }\end{array}$ \\
\hline Case 1 & 14 & $\mathrm{~F}$ & 12 & 32.8 & 15.1 & 3 \\
Case 2 & 12 & $\mathrm{~F}$ & 12 & 44.0 & 21.2 & 16 \\
Case 3 & 13 & $\mathrm{~F}$ & 24 & $\mathrm{NK}$ & $\mathrm{NK}$ & 3 \\
Case 4 & 13 & $\mathrm{M}$ & 24 & 24.2 & 17.8 & 0 \\
Case 5 & 11 & $\mathrm{M}$ & 4 & 38.0 & $\mathrm{NK}$ & 7 \\
\hline
\end{tabular}

$\mathrm{NK}=$ not known.

vision deteriorated such that she was unable to see the school blackboard. Over the next six months she underwent cataract surgery with contact lens prescription. Data on her initial blood glucose and $\mathrm{HbA}_{1}$ levels are not available.

CASE 4

A 13 year old boy presented to an ophthalmologist in 1979 with a six month history of progressive visual deterioration. He had been unwell for two years with weight loss, lack of energy, and recurrent infections. He experienced polyuria and polydipsia for one year. His blood glucose concentration was $24.2 \mathrm{mmol} / 1$ and $\mathrm{HbA}_{1} 17.8 \%$. His visual acuity was $3 / 60$ in both eyes and bilateral snowflake cataracts were confirmed on admission. He showed a gradual increase in his cataracts over the next three years. In 1982 the left lens showed an increased density of cataract formation associated with a deterioration of vision (6/60), whereas the right lens showed only a posterior subcapsular cataract with a vision of $6 / 12$. By 1984 his left vision was poor with a dense cataract. Surgery was not performed at that stage, but, in 1990, to visualise his fundus, he underwent left cataract extraction with intraocular lens implantation and right lens surgery in 1991. There is no background retinopathy.

CASE 5

An 11 year old boy had an unusual presentation in 1994, being unwell for four months. He reported progressive listlessness and polyuria for two months, but no polydipsia. His acute presentation was with swelling of his face, tense ascites, and gross oedema of his legs for two days. A urine dipstick test showed heavy proteinuria and slight glycosuria. $\mathrm{He}$ was thought to have nephrotic syndrome and was treated with steroids (prednisolone), after which he went into diabetic ketoacidosis within 24 hours. His initial management was complicated with problems of blood sugar estimation due to lipaemic serum, but he had a recorded blood glucose level of $38 \mathrm{mmol} / \mathrm{l}$. He was managed with low dose insulin using the diabetic ketoacidosis protocol. The oedema and proteinuria disappeared within a week and steroids were slowly withdrawn thereafter. His diabetes persisted and seven months after diagnosis he failed a school eye test and was prescribed spectacles by an optician who noted a lens opacity in his right eye. Nine months after diagnosis his visual acuity deteriorated and bilateral posterior subcapsular cataracts were confirmed. Twenty months after presentation his vision was $6 / 9$ in the right eye and $6 / 6$ in the left with spectacles. The posterior subcapsular cataracts have not deteriorated. Fundus examination showed no evidence of retinopathy.

\section{Discussion}

We have observed four important clinical features in the five newly diagnosed diabetic children who developed early cataracts. These are: (a) the prolonged duration of symptoms before diagnosis, ${ }^{39}$ (b) a high $\mathrm{HbA}_{1}$ level at diagnosis, ${ }^{34-10}$ (c) a distinct preponderance of girls, ${ }^{179}$ and (d) an adolescent age group. ${ }^{1}$

The development of dense cataracts and associated visual loss is a serious complication of diabetes in young children and adolescents. The pathogenesis of diabetic cataracts in humans is not well understood. The fact that clinically significant cataracts develop in only a small percentage of diabetic children suggests that the degree of hyperglycaemia alone may not be the only factor involved in cataract formation. ${ }^{89}$

The role of aldose reductase enzyme in the pathogenesis of diabetic cataracts in animal models has been well documented. ${ }^{13-18}$ Aldose reductase is predominantly present in the lens epithelium and, to a lesser extent, in the outer cortical fibres. Aldose reductase shows species heterogeneity. It is a highly conserved and inducible enzyme, the physiological role of which is to enable cells to adjust the osmolality of cytoplasm in response to changes in extracellular tonicity. ${ }^{17}$

When the lens epithelium, which is not dependent on insulin for glucose uptake, is exposed to raised extracellular osmolality (as in hyperglycaemia in diabetes) it responds with an excessive flux of glucose to sorbitol by the polyol pathway. The accumulation of intracellular sorbitol exerts osmoprotection and prevents cell shrinkage. The excessive accumulation of sorbitol, however, causes an increased osmotic load within the lens causing swelling, fibre breakdown, and opacification (the osmotic hypothesis). Other mechanisms, including glycation and oxidative stress, may also be responsible for lens opacification. Objections have been raised about the role of aldose reductase and the osmotic hypothesis in the formation of cataracts, ${ }^{15}$ although there is some evidence of the induction of aldose reductase enzyme in animals. ${ }^{19}$ Information on the human lens regarding the activity ${ }^{20}$ and heterogeneity of aldose reductase is limited.

We propose that the likely mechanism for the formation of metabolic cataracts is the induction and increased synthesis of aldose reductase due to prolonged exposure to hyperglycaemia associated with an unusually long duration of symptoms before diagnosis. A similar metabolic state exists in children and adults with poor diabetic control, which may explain the failure of aldose reductase inhibitors to prevent the complications of diabetes in human trials, ${ }^{22} 23$ in contrast with animal experiments, ${ }^{24}$ as by the time the aldose reductase inhibitors were started, the metabolic abnormalities had already caused irreversible changes in tissues such as the lens and 


\section{Key messages}

- Metabolic cataracts may occur in newly diagnosed insulin dependent diabetes, but are rare

- Metabolic cataracts are more likely to occur in children who have prolonged poor control or who present with prolonged duration of symptoms before diagnosis

- The lens of the eye should be examined in all newly diagnosed cases of insulin dependent diabetes, especially those with blurred vision, to diagnose cataracts early

- If lens opacities are suspected, specialist ophthalmological opinion should be sought and, if required, surgery offered to improve the quality of life

nerves. Why cataracts in general, and specifically metabolic cataracts, are more common in girls is not clear. There is no information on aldose reductase levels being different between the sexes. The interesting observation of the occurrence of these cataracts during adolescence may be related to higher aldose reductase levels in young lens epithelium ${ }^{21}$ and perhaps other physical characteristics of the lens in young people. ${ }^{15}$

Further experimental studies, clinical observations, and the collection of laboratory data in these rare patients by diabetologists, ophthalmologists, and paediatricians might help to improve our understanding of the pathogenesis and methods of prevention of lens opacification and other diabetic complications.

From our experience of early cataract formation in young people with diabetes mellitus we recommend that the lens and the retina of the eyes should be examined by an experienced doctor at the onset of diabetes in all children, especially in those who present with prolonged duration of symptoms before diagnosis or who report persistently blurred vision. If lens opacification is suspected, then assessment should be made by an ophthalmologist as early surgical intervention may be required to maintain the quality of life and education in these children.
1 Caird FI, Pirie A, Ramsell TG. Diabetes and the eye. Oxford: Blackwell Scientific, 1969: 127-39.

2 Nabarro JDN. Diabetes in the United Kingdom: a personal series. Diabetic Med 1991;8:59-68.

3 Ehrlich RM, Kirsch S, Daneman D. Cataracts in children with diabetes mellitus. Diabetes Care 1987;10:798-9.

4 Phillip M, Ludwick DJ, Armour KM, Preslan MW. Transient subcapsular cataract formation in a child with diabetes. Clin Pediatr (Phila) 1993;32:684-5.

5 Brown CA, Burman D. Transient cataracts in a diabetic child with hyperosmolar coma. Br f Ophthalmol 1973;57: 429-33.

6 Bilginturan AN, Jackson RL, Ide CH. Transitory cataracts in children with diabetes mellitus. Pediatrics 1977;60:106-

7 Asmal AC, Winning TJ, Leary WP, Dayal B. Blindness from metabolic cataract: a presenting manifestation of diabetes mellitus. S Afr Med $\mathcal{F}$ 1977;52:269-70.

8 Lebinger TG, Goldman KN, Saenger P. Bilateral cataracts as the initial sign of insulin dependent diabetes mellitus in a child. Am f Dis Child 1983;137:602-3.

9 Lang-Muritano M, La Roche GR, Stevens JL, Gloor BRP, Schoenle EJ. Acute cataracts in newly diagnosed IDDM in five children and adolescents. Diabetes Care 1995;18:1395-

10 Alouf B, Pascaul AG. Cataracts as the presenting feature of diabetes mellitus in a child. Clin Pediatr (Phila) 1996;35: 37-9

11 Vinding T, Nielson NV. Two cases of acutely developed cataract in diabetes mellitus. Acta Ophthalmol 1984;62:373-

12 Chalmers J, Herlihy OH, MacDonald M, Campbell W. Metabolic cataract causing loss of vision in newly diagnosed insulin censing loss of vision in newly Diabetes International 1995;12:242-3.

13 Kinoshita JH, Kador P, Catiles M. Aldose reductase in diabetic cataracts. FAMA 1981;246:257-61.

14 Kinoshita JH. Aldose reductase in the diabetic eye. XLIII Edward Jackson memorial lecture. Am f Ophthalmol 1986; 102:685-92.

15 Lightman S. Does aldose reductase have a role in the development of ocular complications of diabetes. Eye 1993;7: $238-41$.

16 Bron AJ, Sparrow J, Brown NAP, Harding JJ, Blakytny R. The lens in diabetes. Eye 1993;7:260-75.

17 Tomlinson DR. Aldose reductase: its importance in diabetes. Practical Diabetes 1994;11:51-5.

18 Tomlinson DR. Aldose reductase inhibitors and the complications of diabetes mellitus. Diabetic Med 1993;10:214-30.

19 Ghahary A, Luo J, Gong Y, Chakrabarti S, Sima AAF, Murphy LJ. Increased renal aldose reductase activity, immunoreactivity and mRNA in streptozocin-induced diabetic rats. Diabetes 1989;38:1067-71.

20 Varma SD, Schocket SS, Richards RD. Implications of aldose reductase in cataracts in human diabetes. Invest Ophthalmol Vis Sci 1979;18:237-41.

21 Jedziniak JA, Chylack LT, Cheng HM, Gillis MK, Kalustian AA, Tung WH. The sorbital pathway in human lens: aldose AA, Tung WH. The sorbital pathway in human lens: aldose Sci 1981;20:314-25.

22 Sorbinil Retinopathy Trial Research Group. A randomised trial of sorbinil, an aldose reductase inhibitor in diabetic retinopathy. Arch Ophthalmol 1990;108:1234-44.

23 Tromp A, Hooymans JM, Barendsen BC, Van Doormall JJ. The effects of an aldose reductase inhibitor on the progression of diabetic retinopathy. Doc Ophthalmol 1991;78:1539.

24 Kador PF, Akagi Y, Kinoshita JH. Diabetic cataracts in animal models: prevention and reversibility with aldose reductase inhibitors. Diabetes Med 1985;2:194-6. 